\title{
Seasonal Changes in the Silica Content of Natural Waters in Relation to the Phytoplankton.
}

\author{
By \\ W. R. G. Atkins, Sc.D. (Dubl.), F.R.S. \\ Head of the Department of General Physiology at the Plymouth Laboratory.
}

With 3 Figures in the Text.

In a previous paper (1923) it was shown that the colorimetric method of Diénert and Wandenbulcke (1923) was suitable for studying silica concentrations down to a limit of $0 \cdot 2-0 \cdot 15 \mathrm{mg}$. per litre without concentrating the solution, the liquid under examination being, after the addition of the reagents, close to $\mathrm{pH} 2$. The method consists of the addition of 2 c.c. of a 10 per cent solution of ammonium molybdate to 100 c.c. of the water to be tested. This is followed by the addition of four drops of a 50 per cent (by volume) solution of sulphuric acid. A yellow colour results, which reaches its maximum in ten to twenty minutes, after which it remains constant for some time. The authors named standardised their solutions against silica, but recommend picric acid as affording permanent standards. They find it convenient to make up a solution containing $36.9 \mathrm{mg}$. of picric acid per litre as giving a yellow colour corresponding to that given by $50 \mathrm{mg}$. p.l. of $\mathrm{SiO}_{2}$ in solution as silicate, and in this the writer has followed them. The method has since been largely used by Thresh and Beale (1925), who consider it as accurate as the gravimetric method, but use $40 \mathrm{mg}$. of picric acid as equivalent to $50 \mathrm{mg}$. of silica. The excessively minute amount of silica present in sea-water renders an even more delicate method desirable, and using 100 c.c. of water compared against a standard corresponding to $0.5 \mathrm{mg}$. per litre it was previously reported possible to detect silica down to $0.15 \mathrm{mg}$. p.l., which means a scale reading of 30 c.c. in the Hehner cylinder used for comparison. With increased practice the writer has since been able to match tints down to a scale reading of 8 c.c., which appears to be indistinguishable from pure water; such a reading corresponds to $0.04 \mathrm{mg}$. p.l., so when this is recorded in a table it must be understood that there may be any lesser quantity ; this amount is tabulated as $40 \mathrm{mg}$. per cubic metre, as the milligram per cubic metre is the most convenient unit to adopt for recording the minor constituents of sea-water; for fresh water these numbers are parts per thousand million, but owing 
to the greater density of sea-water the expression is not quite accurate when applied to the latter. Though readings below 8 c.c. cannot be distinguished from pure water, yet above this differences of 4 c.c., or possibly 2 c.c., may be distinguished, namely, 0.02 or $0.01 \mathrm{mg}$. p.l. Since only 100 c.c. is used the actual amounts distinguished are 0.002 to 0.001 $\mathrm{mg}$. Gravimetric estimations necessarily involve the concentration of filtered sea-water, usually carried out at boiling-point or near it. As previously mentioned, silica, which has escaped filtration, may thus be brought into solution. It depends on how efficiently the finest particles have been removed. That solution may take place was shown by evaporating to dryness, in a nickel dish, sea-water found to contain $0 \cdot 16 \mathrm{mg}$. p.l. $\mathrm{SiO}_{2}$; on cooling and making up to 100 c.c. with distilled water the total soluble silica was found to be $0.54 \mathrm{mg}$. p.l. Filtration through a single Whatman No. 41 filter paper seems, however, to remove all silica or silicate in suspension, for before filtering, after filtering, after evaporating to dryness in a platinum dish and in a nickel dish and making up again to the original volume, a sample of sea-water was found to give the following values, respectively, $0 \cdot 33,0 \cdot 33,0 \cdot 33,0 \cdot 32 \mathrm{mg}$. p.l. In a silica dish, however, $0 \cdot 84 \mathrm{mg}$. p.l. was obtained.

It has been established that the presence of phosphate in the water introduces no error into the silicate estimation, for $0.5 \mathrm{mg}$. p.l. of $\mathrm{P}_{2} \mathrm{O}_{5}$ yields a tint equivalent to $0.08 \mathrm{mg}$. p.l. silica, whereas only in the deeper ocean water is as much as $0.05 \mathrm{mg}$. p.l. of $\mathrm{P}_{2} \mathrm{O}_{5}$ found.

When estimating silicate in water near the coast, or in certain fresh waters, a yellowish or brownish tint may be observed. When a blank without the reagents has shown a tint greater than a scale reading of 8 c.c., the limit for pure water, a suitable correction has been applied. Thus were the water alone to match a $0.5 \mathrm{mg}$. p.l. standard at 24 c.c., using 100 c.c. of the sample, then $0 \cdot 12$ should be deducted for the tint, as the colour is equivalent to that amount of silica. To be strictly accurate the blank reading, 8 c.c., should previously have been deducted, viz. $24-8=16$, therefore deduct $0 \cdot 08$. This, however, was not done as the tint correction is only approximate unless the amount is small and the colour match is seldom exact. Such tints are often met with in fresh water and in the water of Plymouth Sound, but never in the open sea.

\section{Silicate Content of Fresh Water.}

In general fresh water is far richer in silicate than is the sea. The seasonal changes were studied (Atkins and Harris, 1924 and 1925) during 1923 and 1924 in two fresh water ponds, one pipe supply from a shallow well and in Plymouth tap water. The latter is very constant at around $3.3 \mathrm{mg}$. p.l., or $3300 \mathrm{mg}$. per $\mathrm{m}^{3}$. The shallow well supply varied from 
about 2 to $6 \mathrm{mg}$. p.l., the minimum being in February and the maximum in July. These variations were possibly connected with rainfall, and possibly with the increase in temperature favouring the solution of the silicates. Staddon reservoir, in part supplied from this well, fell from about $4 \mathrm{mg}$. p.l. in March, 1923, to under 2 in June, it then rose sharply to an August maximum of about $8 \mathrm{mg}$. p.l., reaching a minimum of less than 2 in January. The other pond rose from less than 1 mg. p.l. in September to over 2 in late December, falling to 0.5 in March. The changes are undoubtedly complex, for in addition to temperature and evaporation effects the removal of silica by diatoms must not be neglected. This was probably the explanation of the spring decrease. The hydrogen ion concentration of the water is also, it appears, of importance, since mineral matter in suspension is more likely to have silicates dissolved out from it when the alkalinity is great. The question is in need of further observational and experimental study.

\section{Silicate Content of Sea-water.}

A series of analyses of water from the $\mathrm{L}$ and $\mathrm{E}$ series of stations are shown in Table 1. The exact positions of these may be found in this Journal, 1922, 12, 747 and 755, but it may be explained that the $\mathrm{L}$ series are on the line from the Laboratory to the Eddystone, and the E series on the Ushant line from the Eddystone. Inspection of the table shows that silicate diminishes from the Sound to the open sea, and there is also perhaps a slight diminution from E1 to Ushant, E3. A few typical results are shown in Fig. 1.

In addition there is a well-marked seasonal change, at E1 a winter value of $200-240$ falls to $40-80$ in April to June. This is followed by a rise 100-160 in October, but in both 1923 and 1925 - 1924 was omittedthe November value is only about $70 \mathrm{mg}$. per $\mathrm{m}^{3}$. The high values for July, 1925, are suspect, as thirteen days elapsed between collection and analysis, the weather, moreover, was hot. There was thus the possibility of matter in suspension and the glass of the bottles being attacked. It was previously shown (1923) that storage in the spring-clip sample bottles of hard green glass did not result in the solution of more than $10 \mathrm{mg}$. per $\mathrm{m}^{3}$ in five days. In specially warm weather this may be somewhat increased. It is certainly a cause of error in some of the results recorded in Table 2, in which of necessity analysis was delayed. Their substantial accuracy is, however, unimpaired. In future work an attempt will be made to avoid this error by coating the bottles with paraffin wax. Even if it be allowed that the El results for July are high, the error cannot be more than about $40 \mathrm{mg}$. per $\mathrm{m}^{3}$ at the most. This July rise is in keeping with Brandt's rise in June. 
TABLE 1.

Silicate Content of Sea-water at L and E Stations.

Silicate as $\mathrm{SiO}_{2}$ in mg. per $\mathrm{m}^{3}$.

\begin{tabular}{|c|c|c|c|c|c|c|c|c|c|c|c|c|c|c|c|c|c|}
\hline & \multicolumn{3}{|c|}{1923.} & \multicolumn{4}{|c|}{1924.} & \multicolumn{8}{|c|}{1925.} & \multirow{2}{*}{$\begin{array}{l}1926 . \\
12 / 1\end{array}$} \\
\hline & & $15 / 10$ & $7 / 11$ & $10 / 12$ & $15 / 2$ & $8 / 4$ & $17 / 6$ & $17 / 2$ & $14 / 3$ & $22 / 4$ & $3 / 6$ & $9 / 7$ & $5 / 8$ & $1 / 10$ & $11 / 11$ & $11 / 121$ & \\
\hline L1) & & 500 & 1 & 600 & 520 & - & & - & 420 & - & 330 & - & - & - & 270 & & 910 \\
\hline L2 & & 350 & 420 & 580 & ) & 170 & 80 & - & - & - & 210 & 200 & 150 & 280 & 570 & 130 & 760 \\
\hline L3) & & & \{ & 490 & $\int 420$ & - & & - & - & 70 & 120 & 170 & - & - & 180 & $\int-$ & 330 \\
\hline $\mathrm{L} 4$ & & - & $\int 70$ & 360 & & 130 & - & - & 180 & - & - & - & 140 & 160 & 190 & 90 & 130 \\
\hline L5 a & ind 6 & -- & - & 280 & 200 & - & - & - & 250 & - & 80 & - & - & - & 90 & 90 & 110 \\
\hline E1 & $\mathrm{m} \quad 0$ & 100 & 70 & 90 & 200 & 80 & 60 & 240 & 160 & 40 & 40 & 150 & 80 & 160 & 70 & 90 & - \\
\hline & , 40 & 100 & - & 150 & - & - & 100 & - & - & - & 40 & - & 70 & 150 & 70 & 90 & - \\
\hline &, 70 & 100 & - & 200 & 200 & 80 & 140 & - & 160 & 70 & 40 & 150 & 80 & 100 & 70 & - & - \\
\hline E2 & $\because \quad 0$ & - & 70 & - & - & - & - & - & & - & - & 140 & - & - & - & $130^{*}$ & - \\
\hline &,, 80 & - & - & - & - & - & - & - & & - & - & 150 & - & - & - & $100^{*}$ & - \\
\hline E3 &, 0 & - & - & - & 180 & - & - & - & & - & - & 120 & - & - & - & - & - \\
\hline &, 100 & - & 70 & - & 180 & - & - & - & & - & - & 120 & - & - & - & - & - \\
\hline & nalysed & $17 / 10$ & $9 / 11$ & $11 / 12$ & $26 / 2$ & $5 / 5$ & $20 / 6$ & $21 / 2$ & $23 / 3$ & $23 / 4$ & $4 / 6$ & $22 / 7$ & $7 / 8$ & $5 / 10$ & $13 / 11$ & $18 / 12$ & $13 / 1$ \\
\hline
\end{tabular}


Brandt (1920) has recorded a seasonal change in the Baltic, silicate as silica varying from $900 \mathrm{mg}$. per $\mathrm{m}^{3}$ in February to 600 in May, followed by a rise in June. Bottom water in February contained $1150 \mathrm{mg}$. As the Baltic receives large accessions of fresh water and is land-locked, it is to be expected that its water should be richer in silicate than is the English Channel and the Atlantic.

The comparatively shallow water of the English Channel affords no

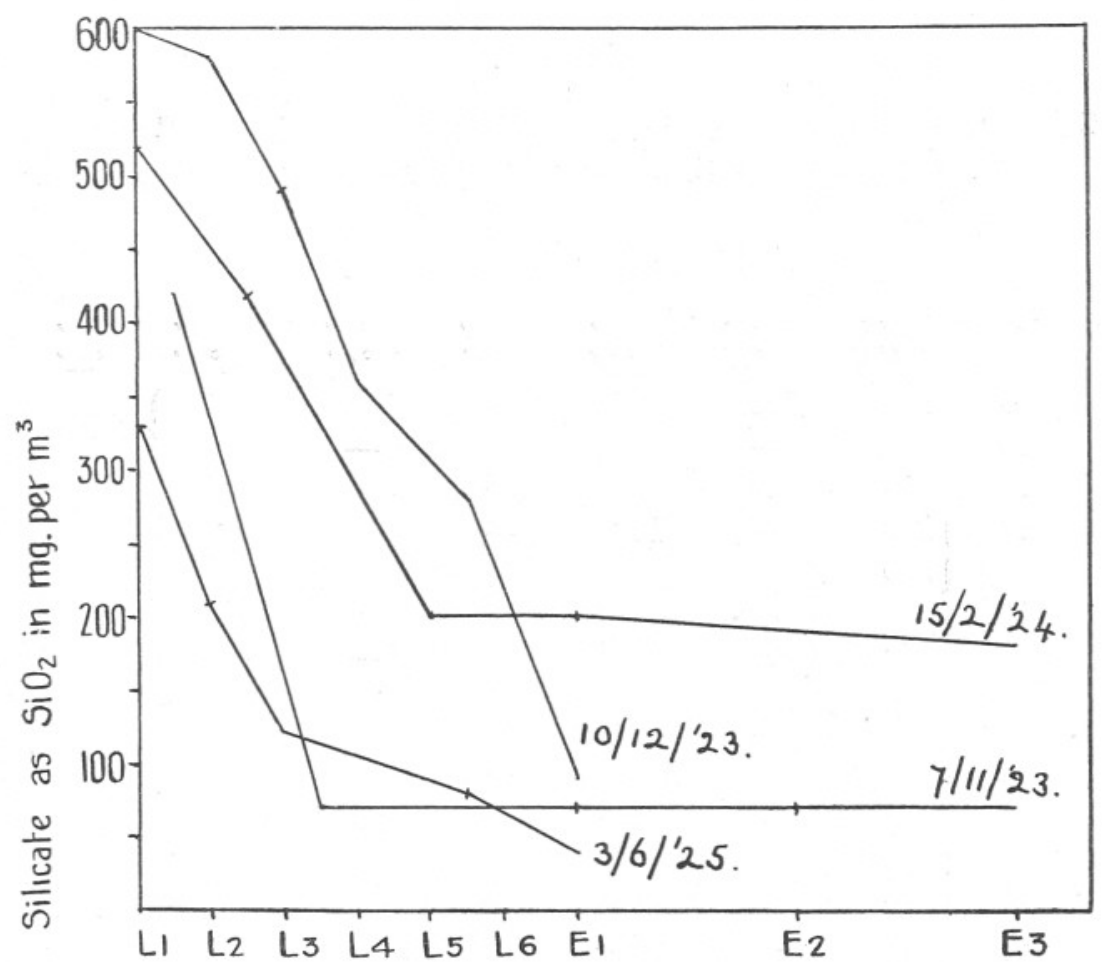

Fig. 1.-Decrease of silicate from Plymouth Sound to open sea of English Channel. The $\mathrm{L}$ stations are at approximately equal distances apart and E2 is midway between E1 and $\mathrm{E} 3$, but the distances are not shown to scale, that between the $\mathrm{E}$ stations being relatively much reduced.

decisive proof of the variation in silicate with increasing depth; though the values for E1 on December 10th, 1923, and June 17th, 1924, show decided differences from surface to bottom, yet in other cases, where phosphate analyses showed depletion at the surface, no such changes were observed as regards silicate. It must, however, be remembered that the matching of the very faint tints shown by such dilute solutions of silicate is always a matter of difficulty. Inspection of Table 2, on the contrary, shows an invariable increase with depth in the deeper waters. 
Owing to storage before analysis all the results are probably slightly too high. They agree in affording undoubted evidence of increase in silicate in the deeper waters of the Atlantic, which thus act as reservoirs of this radicle, available only for plant utilisation when brought to illuminated regions along with phosphates and nitrates (Atkins and Harvey, 1925). It may also be noted that the water immediately next the bottom may be considerably richer in silica than that at a relatively slightly lesser depth.

TABLE 2.

Silicate Content in the Faroe-Iceland and Faroe-Shetland Channels, off the S. of Ireland, in the Bay of Biscay, and off Portugal.

Silicate as $\mathrm{SiO}_{2}$ in $\mathrm{mg}$. per $\mathrm{m}^{3}$.

\begin{tabular}{|c|c|c|c|c|c|c|c|}
\hline $\begin{array}{l}\text { Metres. } \\
\text { depth. }\end{array}$ & $\begin{array}{c}62^{\circ} 53^{\prime} \mathrm{N} \\
9^{\circ} 05^{\prime} W\end{array}$ & $\begin{array}{r}61^{\circ} 27^{\prime} \\
4^{\circ} 23^{\prime}\end{array}$ & $\begin{array}{c}61^{\circ} 02^{\prime} \\
3^{\circ} 22^{\prime}\end{array}$ & $\begin{array}{r}49^{\circ} 20^{\prime} \\
8^{\circ} 00^{\prime}\end{array}$ & $\begin{array}{l}50^{\circ} 34^{\prime} \\
11^{\circ} 17^{\prime}\end{array}$ & $\begin{array}{r}45^{\circ} 50^{\prime} \\
9^{\circ} 00^{\prime}\end{array}$ & $\begin{array}{l}37^{\circ} 44^{\prime} \\
13^{\circ} 21^{\prime}\end{array}$ \\
\hline 0 & 150 & 100 & 95 & 110 & 140 & - & \\
\hline 50 & - & - & - & - & - & - & 220 \\
\hline 60 & 140 & 150 & - & 200 & - & - & - \\
\hline 80 & $\left\{\begin{array}{l}200 \\
200\end{array}\right.$ & - & 160 & - & - & - & \\
\hline & & $\{220$ & & & & & 220 \\
\hline 100 & 250 & 250 & 180 & - & - & - & \\
\hline 150 & - & - & - & $*$ & - & -. & \\
\hline 200 & 250 & 250 & - & $*$ & - & - & \\
\hline 300 & - & - & 210 & $*$ & - & - & 250 \\
\hline 400 & $\int \overline{270}$ & 270 & - & $*$ & 200 & - & - \\
\hline 500 & $\{280$ & - & 310 & $*$ & - & - & 280 \\
\hline 800 & $*$ & - & 360 & $*$ & - & 520 & - \\
\hline 900 & * & 310 & $*$ & $*$ & - & - & - \\
\hline 1000 & * & 360 & $*$ & $*$ & 380 & 一 & 450 \\
\hline 2000 & $*$ & $*$ & * & $*$ & $*$ & * & 480 \\
\hline 3000 & $*$ & $*$ & * & $*$ & * & $*$ & $1200 \dagger$ \\
\hline aken & $4 / 7 / 25$ & $6 / 7$ & $6 / 7$ & $12 / 5$ & $14 / 5$ & $8 / 6$ & $12 / 10$ \\
\hline nalysed & $28 / 7 / 25$ & $28 / 7$ & $28 / 7$ & $5 / 6$ & $5 / 6$ & $13 / 7$ & $2 / 11$ \\
\hline
\end{tabular}

The writer is indebted to Mr. H. W. Harvey and the crew of the Salpa for much assistance in obtaining the local samples, to Dr. Bowman and the stafi of the Aberdeen Laboratory for the northern samples, to Mr.

* Denotes bottom has been passed by this.

$\dagger$ Taken Oetober 16 th at $29^{\circ} 59^{\prime} \mathrm{N} ., 15^{\circ} 03^{\prime} \mathrm{W}$. 
G. W. Farran for those off the Irish coast, and to Dr. Stanley Kemp of the R.R.S. Discovery for the interesting series down to 3000 metres.

Making all possible allowance for the error due to solution of silicate from the glass, these open ocean samples afford no evidence that silica is ever completely used up at the surface of the sea. Lack of it cannot, therefore, be held to limit diatom growth, provided always that the diatom is able completely to strip the water of silicate and to utilise even the most minute amounts; this it must be emphasised has never been proved directly, and it is conceivable that just as a chemical pre-

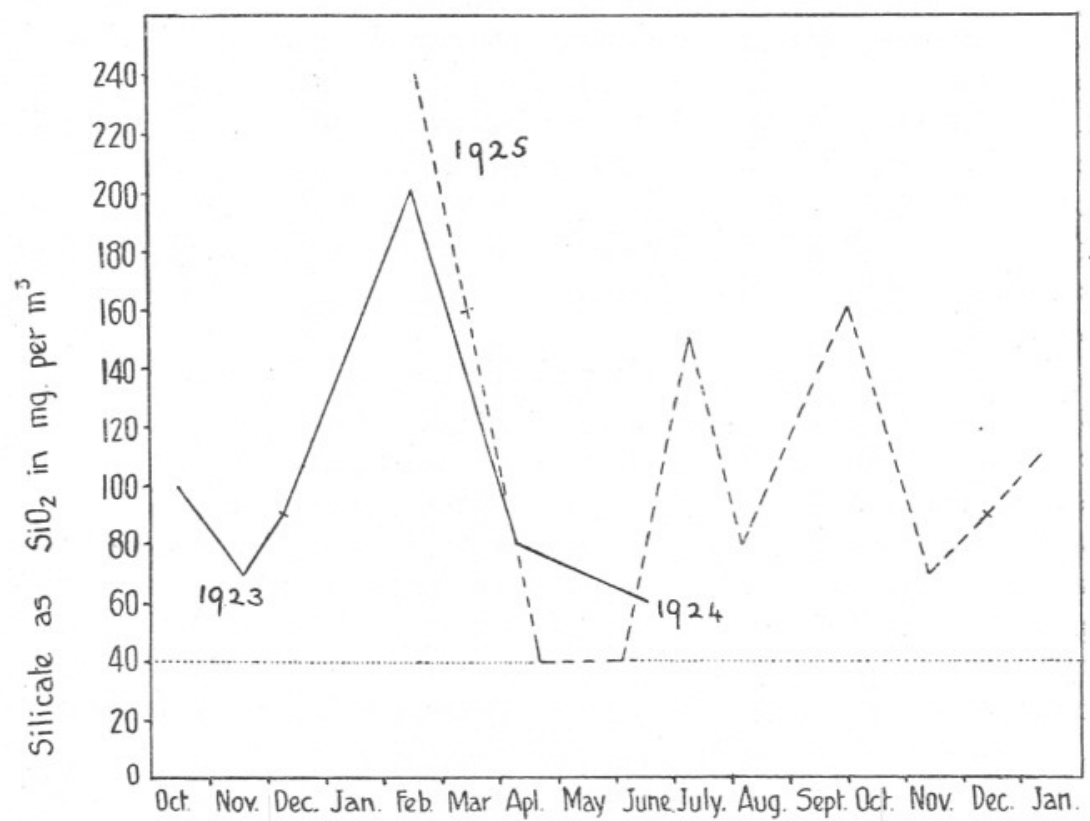

FIG. 2.- Seasonal variations in silicate at Station E1, surface. The dotted horizontal line at $40 \mathrm{mg}$. per $\mathrm{m}^{3}$ may be the true position of the base line, for as explained in the text $40 \mathrm{mg}$. is the limit which can be detected. A value $40 \mathrm{mg}$. may therefore be any lesser amount.

cipitation may - and usually does - still leave a certain minute amount unprecipitated, so also the quite unknown process by which the diatom forms its siliceous test may result in leaving some silica in solution. The analyses recorded in Table 1 and plotted in Fig. 2 show none the less that this precipitation may be so complete that no detectable silicate is left in shallower water, as on April 22nd and June 3rd, 1925, at E1 ; for the recorded value, $40 \mathrm{mg}$. per $\mathrm{m}^{3}$ is, as already explained, equal to the blank or limiting value. The blank amount has not been subtracted, as since the previous paper practice has reduced it from 150 to 40 . The latter value is about the winter maximum value for phosphate as $\mathrm{P}_{2} \mathrm{O}_{5}$, so 
it seems that a more delicate analysis would be required definitely to prove that silica was a limiting factor.

The diminution in silicate which occurs in spring and autumn at E1 points to its removal by diatoms. The fall in spring corresponds with that in phosphate, but in November, 1925, a decrease in silicate corresponded with an increase in phosphate (as shown in a forthcoming paper), though in December an unusual decrease in phosphate corresponded with a slight increase in silicate, giving values for both months identical with those of 1923. It must, however, be remembered that the phosphate content at any time is a resultant value, so that an increase may be accompanied by a diatom outburst if down-grade processes, liberating phosphate from other sources, predominate. The water at E1 is rarely affected at all by outflowing river water, so the low rainfall of the late autumn of 1925 cannot be held to account for the low silicate at E1. The season was, however, clear and sunny, so the decrease in phosphate in December and the low silicate values are probably explained by the rather unusual development of phytoplankton at this period.

In Fig. 3 are shown the periods of silicate diminution; these it may be supposed are proportional to diatom production; the values are obtained by subtracting the silica result for each month from that of the previous month of observation, and then representing a loss of silicate in solution as a gain in silica, precipitated in diatoms, as shown by ordinates above the axis. Below the axis the corresponding amounts of silica gained by the water are shown. This it may be assumed is a closed system; if so the annual increase and decrease should on an average of years be equal. Silicate is, however, brought in by rivers and diatomaceous deposits and sponge spicules are found in various places, so it is an open question whether the ocean silicate cycle is to be regarded as an almost closed one, like the phosphate cycle, or one in which the annual silicate addition is precipitated by living organisms. It seems more probable, however, that a portion of the diatom silica again finds its way into the water of the ocean. The point needs experimental investigation.

If we attempt to construct a balance sheet for the silica in the water at $\mathrm{E} 1$, the maximum winter value $240 \mathrm{mg}$. per $\mathrm{m}^{3}$ minus the minimum shows a utilisation of $200 \mathrm{mg}$. If, however, all the observations showing depletion are taken it is seen that $360 \mathrm{mg}$. was used up and $230 \mathrm{mg}$. regenerated or supplied afresh, the deficit on the turnover being $130 \mathrm{mg}$. If the analyses are correct this figure should also be given by subtracting the initial and final values for the silica content at E1, viz. $240-110 \mathrm{mg}$., namely, 130. The exact agreement is somewhat surprising. It is to be noted that for some unknown reason the silica content at E1 is low this 
winter even though the phosphate content has now recovered its high winter value.

The writer is indebted to Dr. M. V. Lebour for the information that the late autumn of 1925 was a period when Rhizosolenia robusta was specially plentiful in the water off Plymouth. This is a large diatom, just visible to the naked eye, and it reaches approximately its northerly limit of distribution at Plymouth. Other species of this genus, namely, $R$. shrubsolei, $R$. styliformis, and $R$. alata have been far more abundant

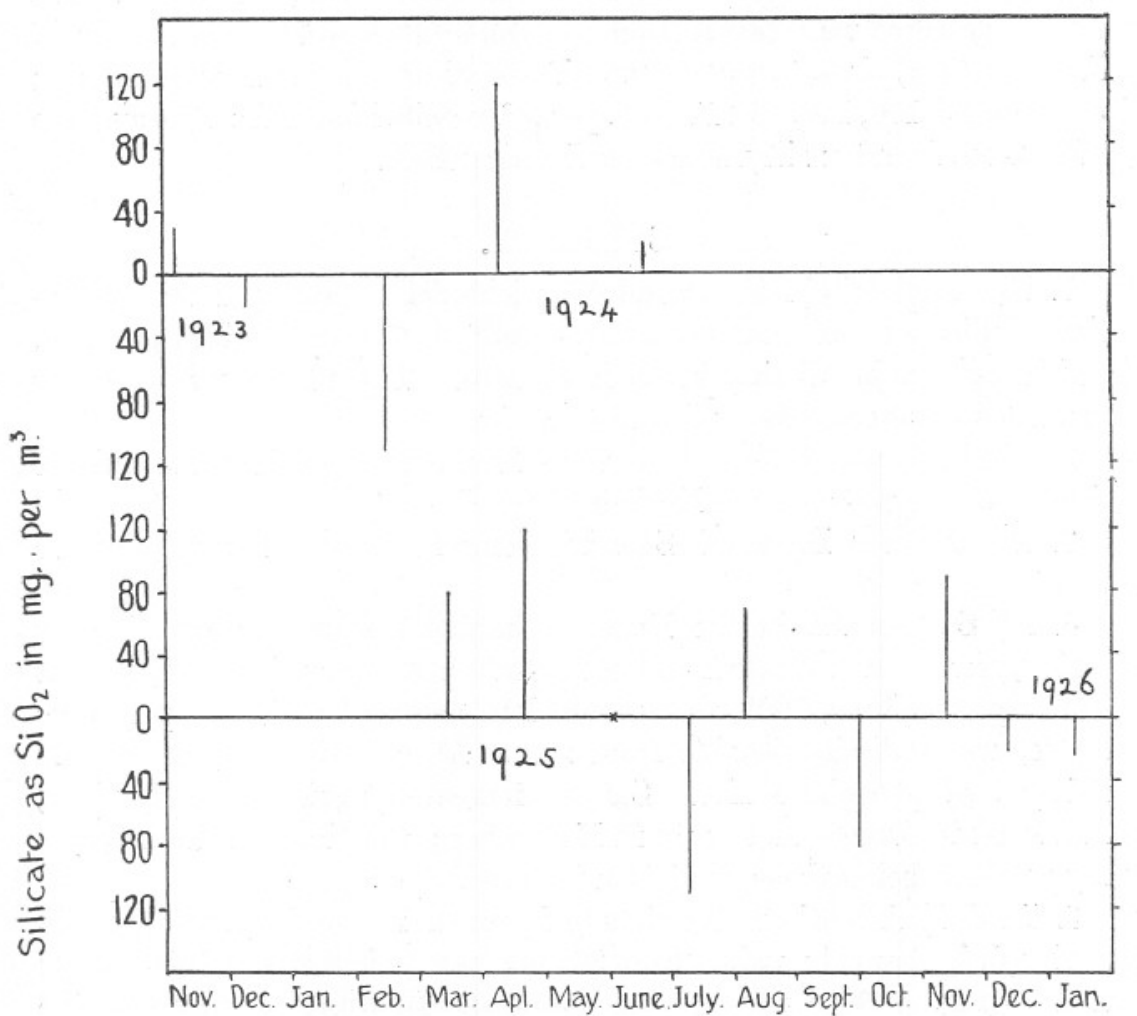

FIG. 3.-Periods of production of diatoms as judged by upward lines, corresponding to $\mathrm{mg}$. per $\mathrm{m}^{3}$ of silicate, as silica, used up. Downward lines denote enrichment in silicate, due to its regeneration from the decay of diatoms or other sources.

than usual over the same period and took the place of Biddulphia regia, $B$. sinensis, and $B$. mobiliensis, which were not as plentiful as usual. The diatom distribution was unlike that of any other year of the last ten. It seems possible that the abundance of $R$. robusta is not unconnected with the fall in silica in November shown in Fig. 3, though the actual value reached was the same as in 1923 .

Interesting light is thrown on the silica content of the Atlantic Ocean, NEW SERIES. - Vol. XIV. No. 1. MaIiCH, 1926. 
surface water in winter, by a series of samples taken by the s.s. Hildebrand between Para and about $2 \frac{1}{2}^{\circ}$ west of Ushant. The most southerly samples were all consumed in phosphate and nitrate determinations, but four between $6^{\circ} 12^{\prime}$ and $14^{\circ} 15^{\prime} \mathrm{N}$. and $41^{\circ} 36^{\prime}$ and $34^{\circ} 40^{\prime} \mathrm{W}$. respectively, namely, in the open ocean averaged $240 \mathrm{mg}$. per $\mathrm{m}^{3}$, minimum 200 , which may be a little too high on account of solution of glass in warm weather. They were taken from December 19th to 21st, analysed January 13th. The next four samples vary from $170-110 \mathrm{mg}$. per $\mathrm{m}^{3}$, average 140 . They, too, are from the open ocean, the last being east of Madeira. The remaining three were taken (from December 28th to 30th and analysed January 13th) close to the coast of Portugal and in the Bay of Biscay ; they showed 100,120 , and $110 \mathrm{mg}$. per $\mathrm{m}^{3}$, results identical on the average with those found off Plymouth on January 12 th.

\section{SUMMARY.}

1. The method of Diénert and Wandenbulcke permits of the estimation of silicate in solution down to the limit of $0.04 \mathrm{mg}$. of silica per litre, which cannot be distinguished from zero. The phosphate normally present does not interfere with the reaction.

2. All fresh waters examined were found to contain more silicate than does the water of the English Channel.

3. The water of Plymouth Sound is richer in silicate than that of the sea.

4. At Station E1 in the English Channel silicate decreases during spring, from a winter maximum of $200-240 \mathrm{mg}$. per cubic metre, so that from April to June, 1925, the amount left, recorded as $40 \mathrm{mg}$. per cubic metre, was indistinguishable from zero. At this time the water was stripped of phosphate also. Silicate increased again till early July, decreased in August and again in November ; the times of decrease are suggested as being those of diatom increase.

5. In deep Atlantic water silicate is much more abundant than in the English Channel ; values from $360 \mathrm{mg}$. per cubic metre at 1000 metres to $1200 \mathrm{mg}$. at 3000 metres were obtained. In winter at any rate the surface value in the Atlantic is similar to that off Plymouth, about $110 \mathrm{mg}$. per $\mathrm{m}^{3}$ in 1925 .

\section{REFERENCES.}

Atkins, W. R. G. 1923. The silica content of some natural waters and of culture media. Journ. Mar. Biol. Assoc. 13, 151-159.

Atkins, W. R. G., and Harris, G. T. 1924. Seasonal changes in the water and heleoplankton of fresh-water ponds. Sci. Proc. Roy. Dublin Soc., 18, 1-21, and Notes Bot. School, Trinity College, Dublin, 1925, 3, No. 6, 281-301. 
Atkins, W. R. G., And Harris, G. T. 1925. Abstract of above, with three figures. Journ. Mar. Biol. Assoc., 13, 750-754.

Atkins, W. R. G., And Harvey, H. W. 1925. The variation with depth of certain salts utilised in plant growth in the sea. Nature, 116, 784.

Brandt, K. 1920. Über den Stoffwechsel im Meere. 3 Abhandlung. Wiss. Meeresuntersuch. Abt. Kiel, 18, 185-430.

Dí́nert, F., And Wandenbulcke, F. 1923. Sur le dosage de la silice dans les eaux. C. R. Acad. des Sciences, Paris, 176, 1478-1480.

Thresh, J. C., And Beale, J. F. 1925. The examination of waters and water supplies. London. 
